\title{
ESTUDO DA ADIÇÃO DE NIÓBIA EM COMPÓSITO DE MATRIZ ALUMINA COM DISPERSÃO DE ZIRCÔNIA*
}

\author{
Thales Lima Da Silva ${ }^{1}$ \\ Adrieli Oliveira Da Silva² \\ Elton Douglas Heringer ${ }^{3}$ \\ Camila Valentina Ribeiro Portilho ${ }^{4}$ \\ Elias Fagury-Neto ${ }^{5}$ \\ Adriano Alves Rabelo 6
}

\section{Resumo}

As cerâmicas avançadas estão em diversas aplicações técnicas devido à possibilidade de melhoria na tenacidade, ao desgaste e corrosão em altas temperaturas. Neste trabalho avaliou-se 0 aditivo de sinterização $\mathrm{Nb}_{2} \mathrm{O}_{5}$ em teores de $0,2 \%, 0,4 \%$ e 0,6\%vol. no compósito $98,5 \% \mathrm{Al}_{2} \mathrm{O}_{3}$ com dispersão de $1,5 \%$ de $\mathrm{ZrO}_{2}$ nanométrica. Os pós foram misturados em moinhos de bola e as amostras foram conformadas por prensagem uniaxial. Utilizou-se a sinterização convencional a $1450^{\circ} \mathrm{C}, 1500^{\circ} \mathrm{C}$ e $1550^{\circ} \mathrm{C}$ por 1 hora, caracterizando-se a densidade aparente pelo método de Arquimedes e a microestrutura final por microscopia eletrônica de varredura, procurando-se avaliar o efeito inibidor de crescimento de grão da zircônia frente a possibilidade de formação de fase líquida pela adição de nióbia.

Palavras-chave: Fase líquida; Sinterização; Crescimento de grãos.

\section{STUDY OF THE ADDITION OF NIHOBIA IN MATRIX ALUMINA COMPOSED WITH DISPERSION OF ZIRCONIA}

\begin{abstract}
Advanced ceramics are in many technical applications due to the possibility of improvement in toughness, wear and corrosion at high temperatures. In this work the $\mathrm{Nb2O} 5$ sintering additive was evaluated in contents of $0.2 \%, 0.4 \%$ and $0.6 \%$ vol. In the composite $98.5 \% \mathrm{Al} 2 \mathrm{O} 3$ with $1.5 \%$ dispersion of nanometer $\mathrm{ZrO} 2$. The powders were mixed in ball mills and the samples were formed by uniaxial pressing. Conventional sintering was used at $1450^{\circ} \mathrm{C}, 1500^{\circ} \mathrm{C}$ and $1550^{\circ} \mathrm{C}$ for 1 hour, characterizing the apparent density by the Arquimedes method and the final microstructure by scanning electron microscopy, in order to evaluate the inhibitory effect of grain growth Of zirconia against the possibility of formation of liquid phase by the addition of niobium.
\end{abstract}

Keywords: Liquid phase;Sintering; Grain growth.

1 Engenharia de Materiais, graduando, aluno voluntário de Iniciação Cientifica, Instituto de Geociências e Engenharias, Unifesspa, Marabá , Pará, Brasil.

2 Engenharia de Materiais, graduanda, bolsista CNPQ, Instituto de Geociências e Engenharias, Unifesspa, Marabá, Pará Brasil.

3 Engenharia de Materiais, graduando, bolsista CNPQ, Instituto de Geociências e Engenharias, Unifesspa, Marabá,Pará, Brasil.

4 Engenharia de Materiais, graduanda, bolsista PIBIC FAPESPA, Instituto de Geociências e Engenharia Unifesspa, Marabá, Pará, Brasil.

5 Engenheiro Químico, Doutor, Pró Reitor de Graduação, Instituto de Geociências e Engenharias, Unifesspa, Marabá, Pará, Brasil.

6 Engenheiro de Materiais, Doutor, Diretor adjunto do Instituto de Geociências e Engenharias, Instituto de Geociências e Engenharias, Unifesspa, Marabá, Pará, Brasil. 


\section{INTRODUÇÃO}

A busca constante por novos materiais e novas tecnologias, devido a modernização, vem trazendo consigo o estudo de diversos materiais em vastas áreas de aplicação atualmente, como as cerâmicas avançadas, que são elaboradas com matérias primas de alto grau de pureza, e tamanho das partículas apropriados, devido isto, exigem maiores cuidados em suas etapas de processamento evitando assim possíveis contaminações, possibilitando a existência de peças de uso mais especifico, técnico e de maiores desempenho, estando em diversas cerâmicas de alta tecnologia. Cerâmicas estas, que fazem uso de matérias primas que exibem boa resistência à elevadas temperaturas e corrosão, no entanto apresentam baixa tenacidade e, tendo a Alumina $\left(\mathrm{Al}_{2} \mathrm{O}_{3}\right)$, como matriz na maioria dos casos. Neste âmbito a alumina tem grande destaque e é um dos compostos mais utilizados devido suas propriedades, entre elas o elevado módulo de elasticidade, sua alta refratariedade e dureza, sua condutividade térmica que é superior em relação a maioria dos óxidos cerâmicos, em destaque sua alta resistência em baixas e altas temperaturas [1].

Neste artigo foi analisado, um compósito de matriz $\mathrm{Al}_{2} \mathrm{O}_{3} 98.5 \%-1.5 \% \mathrm{ZrO}_{2}$ tendo como aditivo de sinterização a $\mathrm{Nb}_{2} \mathrm{O}_{5}$ incorporado em teores diferenciados em fração de volume da mistura, com o objetivo de aumentar a tenacidade à fratura de cerâmicas à base de alumina, propriedade característica da zircônia. Os aditivos de sinterização, neste caso o óxido de nióbio usado como dopante agindo como aditivo de sinterização, tem uma boa influência na cinética da sinterização da alumina, possibilitando alta taxa de retração e densidades, sendo capaz de inibir o crescimento dos grãos ( ou acelerar o crescimento de grão), dando assim uma maior coesão entre as partículas sinterizadas, promovendo uma maior densificação, [1].

\section{MATERIAIS E MÉTODOS}

Para o processamento deste nanocompósito, foram utilizados como matérias primas; Alumina com teor de $98,9 \%$ de pureza (Alumina Reativa A), Zircônia monoclínica (Tosoh OY) e Nióbia de grau ótico. Este compósito teve sua matriz contida em base de Alumina com dispersão de zircônia $\mathrm{Al}_{2} \mathrm{O}_{3} 98.5 \%-1.5 \% \mathrm{ZrO}_{2}$, e teve incorporação de $\mathrm{Nb}_{2} \mathrm{O}_{5}$ em teores de $0.2 \%$; $0.4 \%$; e $0.6 \%$ em volume da mistura.

Inicialmente preparou-se os pós em suas quantidades ideais, e introduziu-se primeiramente os pós de nióbia para o processo de moagem a úmido, num moinho de jarros, utilizando bolinhas de Zircônia de 3 e $5 \mathrm{~mm}$ de diâmetro, preenchendo cerca de $40 \%$ do volume de um frasco de polietileno sem pigmentação usado para a moagem. Para auxiliar na homogeneização das partículas e se obter uma melhor moagem, foram adicionados $1 \%$ em peso de PVB (Butivar 98) como defloculante, $0.5 \%$ em peso de ácido oleico para exercer função de agente ligante e $5 \mathrm{ml}$ de álcool isopropílico, totalizando 8 horas de moagem. Por conseguinte foi acrescido à mistura, os pós de zircônia para continuação da moagem, adicionando assim mais $15 \mathrm{ml}$ de álcool isopropílico moendo por mais 6 horas. Por fim, para a etapa de homegeneização foi acrescentado os pós de alumina com a inserção de mais $40 \mathrm{ml}$ de álcool moendo pelo tempo de 10 horas, totalizando 24 horas do processo de moagem. 
A barbotina foi seca com jato de ar quente em ambiente aberto ( exposta ao ar ), até os grânulos se soltarem das bolinhas e das paredes do frasco por meio de agitação manual do mesmo. Seguiu-se com o peneiramento da mistura numa malha de \#100, para não permitir a presença de pós aglomerados na mistura. Posteriormente foi realizada a prensagem uniaxial numa matriz cilíndrica com carga aplicada de 180 $\mathrm{MPa}$, assim foram conformados 24 corpos de prova à verde com diâmetro de 10 $\mathrm{mm}$ e com aproximadamente $5 \mathrm{~mm}$ de altura de área de aproximadamente 78.53 $\mathrm{mm}^{3}$. Calculou-se a densidade à verde dos corpos de prova cerâmicos e depois os mesmos foram calcinados à temperatura de $50^{\circ} \mathrm{C}$ por 3 horas $\left(10^{\circ} \mathrm{C} / \mathrm{min}\right)$. Em seguida realizou-se a sinterização das peças nas seguintes temperaturas: $1450^{\circ} \mathrm{C}$; $1500^{\circ} \mathrm{C}$ e $1550^{\circ} \mathrm{C}\left(10^{\circ} / \mathrm{min}\right)$ pelo tempo de 1 hora. Sendo assim, realizou-se a caracterização pelo método de Arquimedes, e microscopia eletrônica de varredura, para analise da microestrutura do material para afins dos objetivos pretendidos neste trabalho.

Tabela 1. Formulações realizadas neste trabalho.

\begin{tabular}{ccc}
\hline $\mathrm{Al}_{2} \mathrm{O}_{3}(\%)$ & $\mathrm{ZrO}_{2}(\%)$ & $\mathrm{Nb}_{2} \mathrm{O}_{5}(\% \mathrm{Vol})$ \\
\hline 98,5 & 1,5 & 0,0 \\
98,5 & 1,5 & 0,2 \\
98,5 & 1,5 & 0,4 \\
98,5 & 1,5 & 0,6 \\
\hline
\end{tabular}

\section{RESULTADOS E DISCUSSÃO}

Com base nos resultados obtidos, foi visto que a temperatura de $1450^{\circ} \mathrm{C}$ foi a que menos influenciou de forma significativa, deixou muitos poros nas amostras envolvendo todas as formulações. No entanto, em $1550^{\circ} \mathrm{C}$ se obteve uma melhor densificação das partículas, analisando o fato de que com aumento do teor de oxido de nióbia, notou-se o aparecimento de grãos maiores e de tamanhos variados, também viu-se o crescimento anormal de grãos, que não precisam necessariamente de altas temperaturas para ocorrer. Ou seja, a adição de nióbia acelerou o crescimento dos grãos como será mostrado nas imagens feitas por Microscopia de Varredura Varredura. Hassan [5] afirmou que o aumento do teor de $\mathrm{Nb2O} 5$ favorece o crescimento anormal dos grãos de Al2O3. No entanto, não observaram fases intergranulares por análises de $M E V$ e sim regiões claras e esparsas na microestrutura das amostras sinterizadas a $1650^{\circ} \mathrm{C}$ as quais identificaram como $\mathrm{Nb} 2 \mathrm{O} 5$.

Como pode se ver na imagem abaixo, uma localização de poro no interior dos grão, o que pode identificar que a densificação foi prejudicada. 


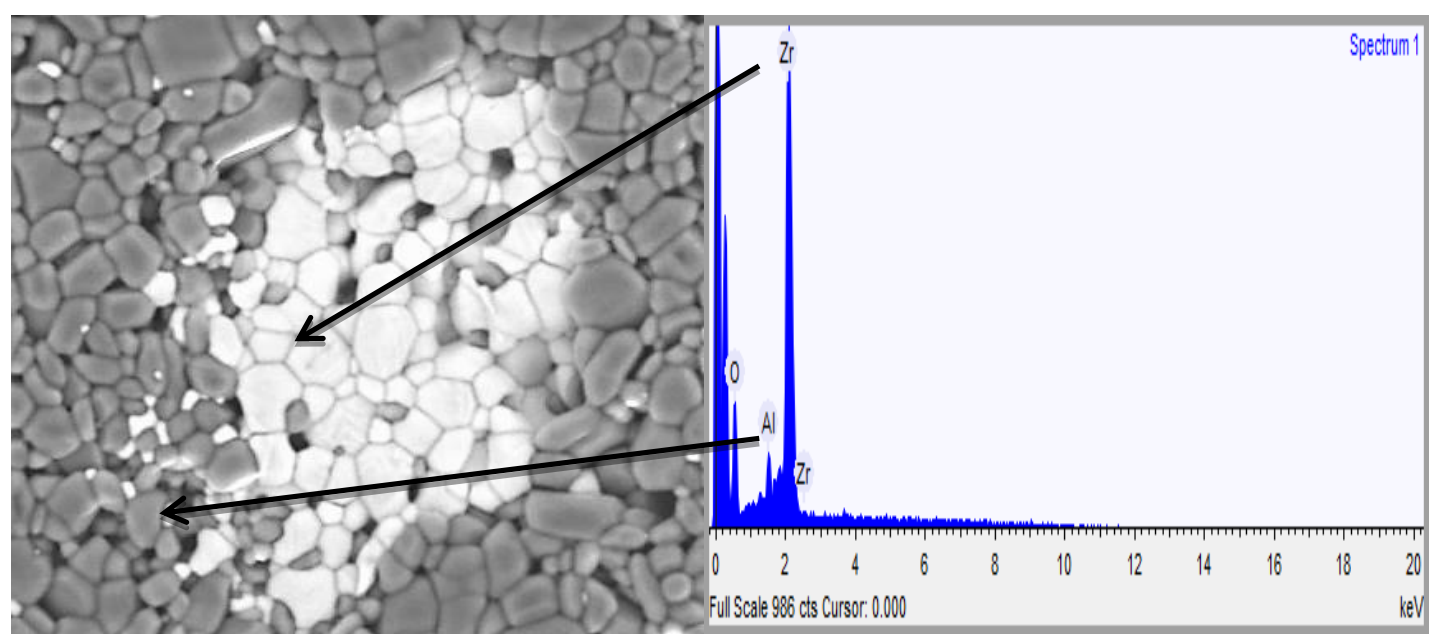

Figura 4. Amostra com $0,4 \%$ em Vol. de $\mathrm{N}_{2} \mathrm{O}_{5}-1500^{\circ} \mathrm{C}$ com auxílio do EDS

A formulação sem uso de dopante teve um melhor desempenho diante da discussão em função dos resultados que foram exibidos e que ainda serão mais à frente, porosidade mínima, e contornos de grão bem formados e definidos, e zircônia bem distribuída.

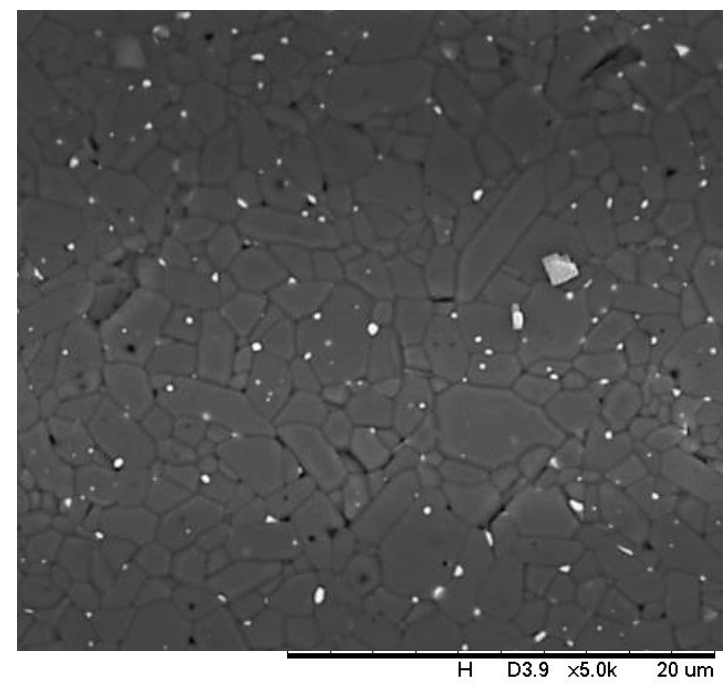

IGE-UNIFESSPA

Figura 5. Amostra com adição de $0,0 \%$ em Vol. de $\mathrm{Nb}_{2} \mathrm{O}_{5}-1550^{\circ} \mathrm{C}$.

No diagrama de fases Alumina/Nióbia, o a $\mathrm{Nb2O} 5$ funde a temperaturas próximas a $1450^{\circ} \mathrm{C}$, havendo então talvez uma interação com a alumina. A Nióbia adicionada pode ter reagido com alguns grãos de alumina, devido terem maior tensão superficial, podem ter formado pequenas quantidades de fase líquida durante a sinterização, fazendo com o que os grãos crescessem. Também vale ressaltar que, a presença de fase vítrea depende da composição, e no caso do trabalho apresentado, estamos lidando com matérias primas de alto grau de pureza, o que diminui a quantidade de fase vítrea. No entanto, não foi vito sinais de fase liquida nas imagens do MEV. 


\subsection{Propriedades Tecnológicas}

Segue abaixo a expressão dos resultados em formas de gráficos em função das temperaturas de sinterização. Absorção em água (AA), Porosidade Aparente (PA) e Densidade Aparente (DA).

A absorção em água foi baixa, como podemos ver no gráfico abaixo, com o aumento da temperatura, a absorção diminuiu. No entanto, o aumento em volume de Nióbia na temperatura de $1500^{\circ} \mathrm{C}$ fez com que as amostras absorvessem mais água.

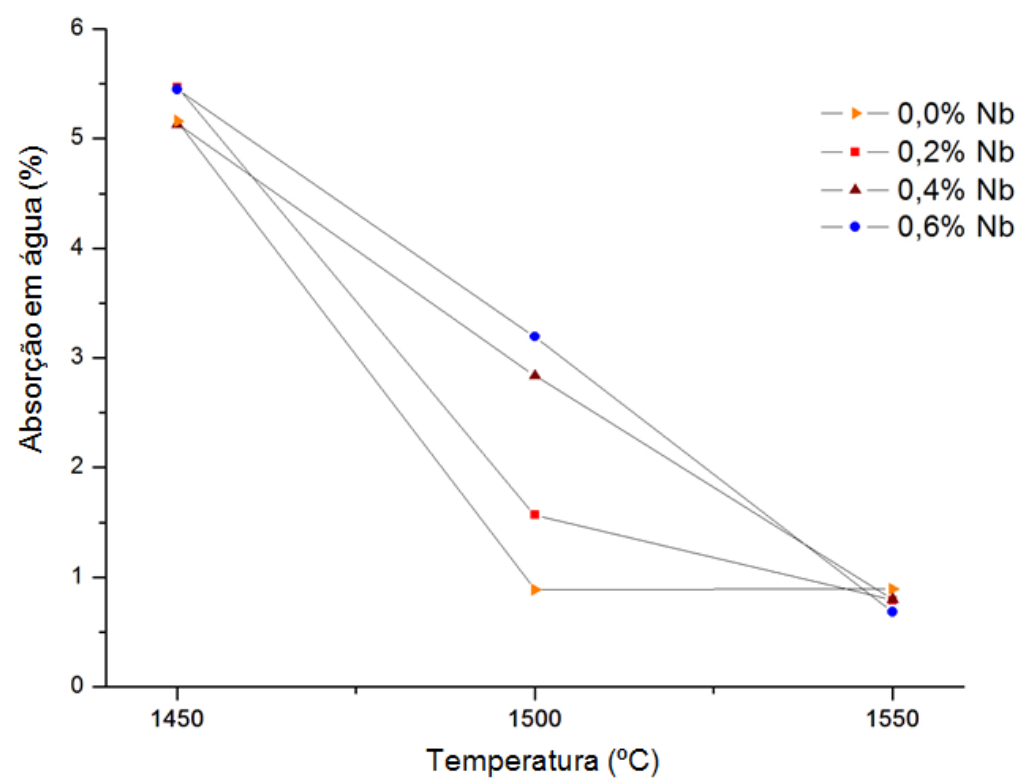

Figura 6. Gráfico de Absorção em água nas três temperaturas de sinterização.

A porosidade aparente seguiu rumos semelhantes ao gráfico acima, neste caso a temperatura de $1500^{\circ} \mathrm{C}$ também foi um ponto de analise delicado. Também neste ponto, o aumento do teor de nióbia fez aumentar a porosidade, entrando em parâmetros mais equilibrados na temperatura de $1550^{\circ} \mathrm{C}$. As temperaturas de 1450 e $1550^{\circ} \mathrm{C}$ mostram claramente que a adição deste dopante não influenciou de forma relevante.

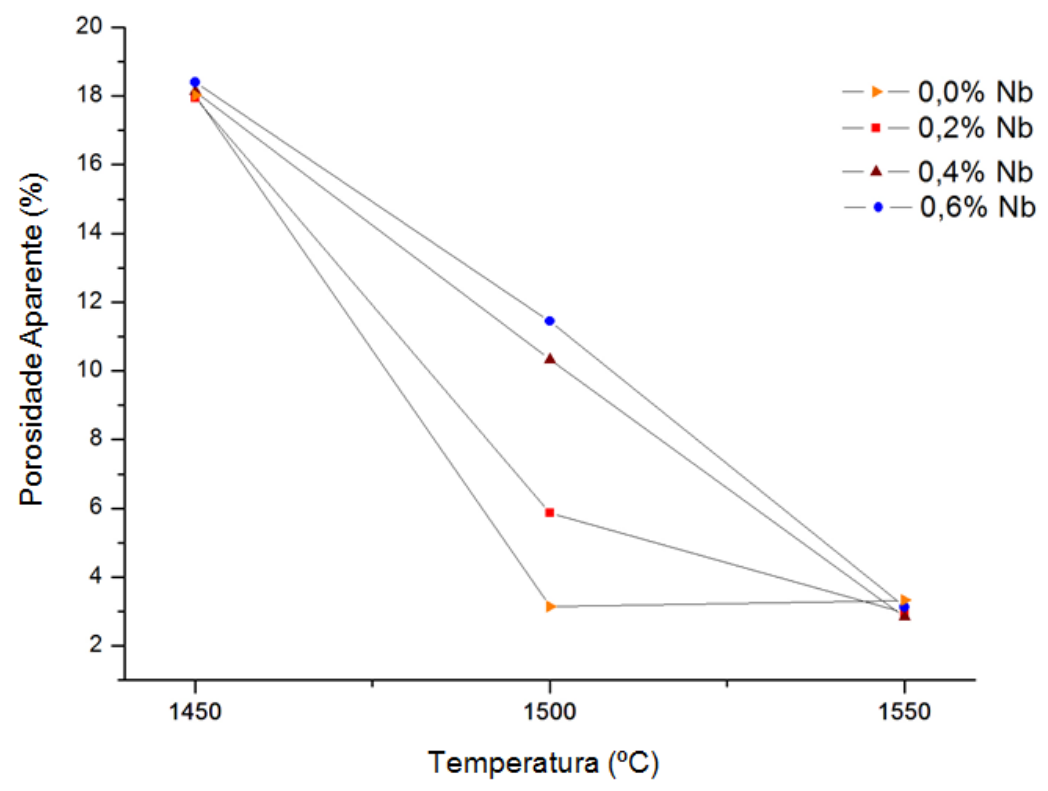


Figura 7. Gráfico de porosidade aparente, nas três temperaturas de sinterização.

A densidade aparente também seguiu da mesma forma, tendo amostras mais densas nas maiores temperaturas, porém, diminuindo a densidade à medida que se aumentava o teor de nióbia, mais uma vez sendo mais visível na temperatura de $1500^{\circ} \mathrm{C}$. Hassan [3] fazendo uma analise entre densidade e porosidade, analisou que 0 aumento do conteúdo de $\mathrm{Nb}_{2} \mathrm{O}_{5}$ aumentou a densidade aparente do corpo e dimiunuiu a sua aparente porosidade, o que não foi obtido com o mesmo exito neste trabalho, e de forma bem visivel na temperatura de $1500^{\circ} \mathrm{C}$, na qual o aumento de $\mathrm{Nb}_{2} \mathrm{O}_{5}$ diminuiu a densidade aparente dos corpos.

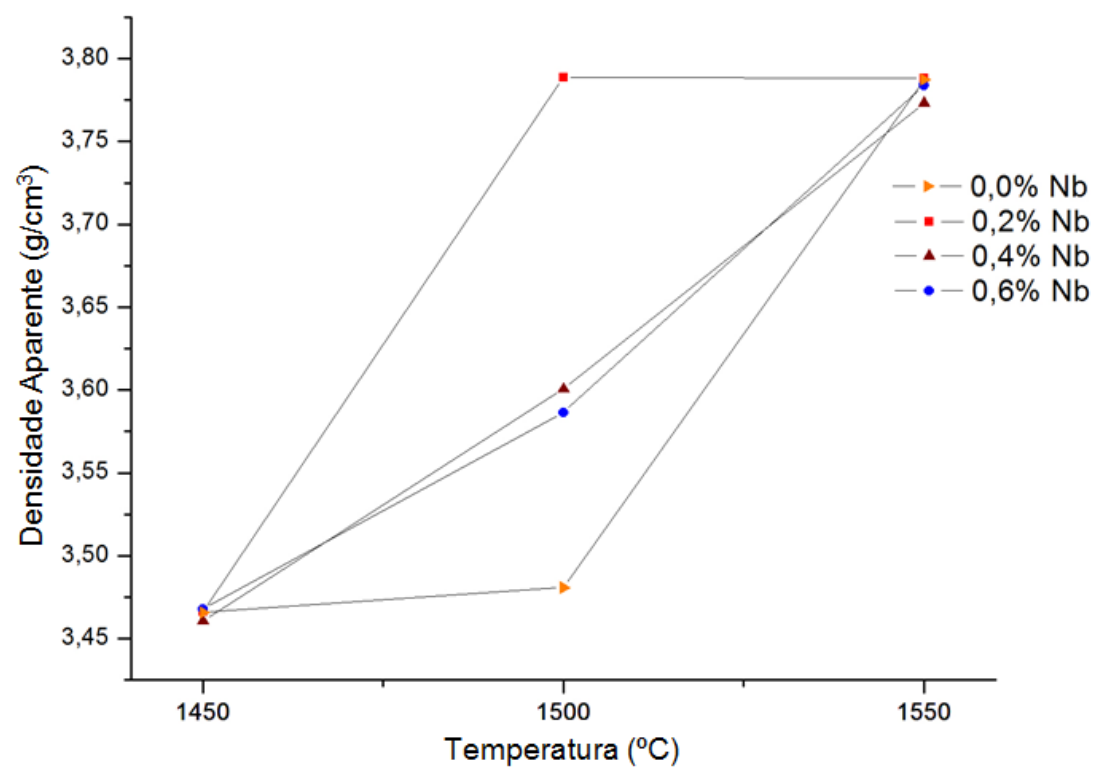

Figura 8. Densidade aparente em função da temperatura de sinterização.

\subsection{Análise mineralógica por Difração de Raios-X}

A análise do DRX perimitiu-nos verificar que independente das variações de teores de $\mathrm{Nb}_{2} \mathrm{O}_{5}$, não se teve alterações significativas nas fases formadas nas três temperaturas usadas no processamento dos corpos. Os gráficos se mantiveram de forma constantes um em relação ao outro. Como resultado, os picos mais predominates foram de alumina na forma de coríndon (c), zicônia (z) e Nióbia na forma $\mathrm{NbO}(\mathrm{n})$. 


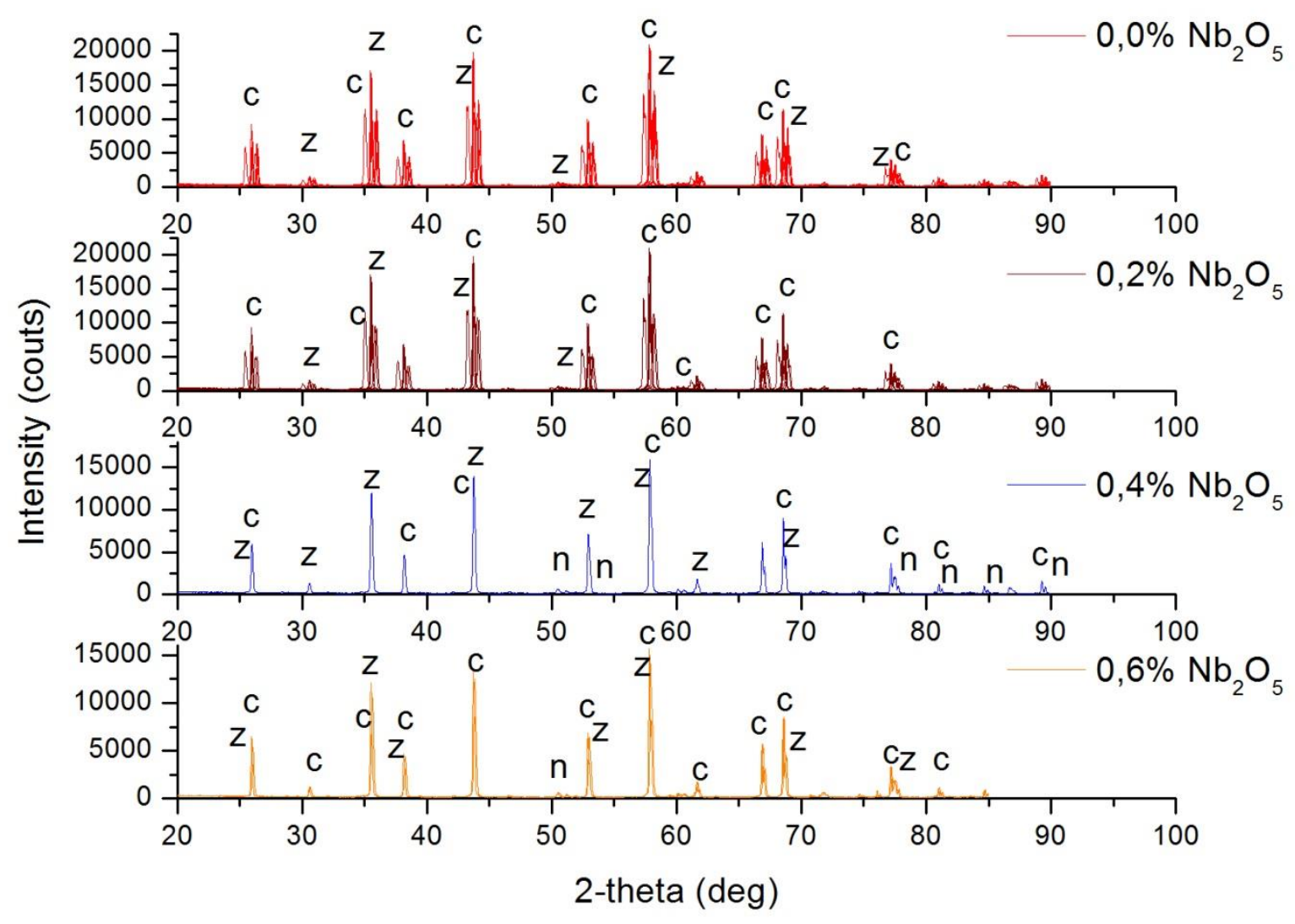

Figura 9. Análise do DRX na temperatura de $1550^{\circ} \mathrm{C}$.

\section{CONCLUSÃO}

Em suma, conclui-se que a presença de $\mathrm{Nb}_{2} \mathrm{O}_{5}$ neste compósito, analisado nas diferentes temperaturas, acarretou um aumento perceptível no tamanho de grão, o que possibilita dizer que, o uso deste aditivo de sinterização numa matriz de alumina, faz com que ele tenha ação de um acelerador de crescimento de grão. Não se obteve melhorias significativas quanto as propriedades tecnológicas citadas. Contudo, as pesquisas devem continuar para que se avalie as propriedades deste compósito para fins de mais conclusões.

\section{Agradecimentos}

Agradeço a Universidade Federal do Sul e Sudeste do Pará e ao IGE (Instituto de Geociências e Engenharias) pelo apoio e suporte dado para a realização deste trabalho. 


\section{REFERÊNCIAS}

[1] JOÃO MARCOS KRUSZYNSKI DE ASSIS. Estudo comparativo de compósitos Alumina Zircônia Tetragonal e de cerâmicas de Alumina aditivada com Nióbia para aplicações estruturais. Dissertação de Mestrado do Curso de Pós-Graduação em Engenharia e Tecnologia Espaciais/Ciência e Tecnologia de Materiais e Sensores INPE São José dos Campos 2008.

[2] J. J. PIERRI ${ }^{1}$, S. C. MAESTRELLI ${ }^{2}$, E. M. J. A. PALLONE ${ }^{2}$, R. TOMASI ${ }^{1}$. Dispersão de nanopartículas de $\mathrm{ZrO}_{2}$ visando produção de nanocompósitos de $\mathrm{ZrO}_{2}$ em matriz de $\mathrm{Al}_{2} \mathrm{O}_{3}$. Cerâmica 51 (2005) 08-12.

[3] A.M. HASSAN ${ }^{A}$, S.M. NAGA ${ }^{B}, M$. AWAAD ${ }^{B}$. Toughening and strengthening of $\mathrm{Nb} 2 \mathrm{O} 5$ doped zirconia/alumina (ZTA) composites. (C) 2014 Elsevier Ltd. All rights reserved. Int. Journal of Refractory Metals and Hard Materials 48 (2015) 338-345.

[4] ACCHAR, W. Produção de Alumina Sinterizada com Adições de Nióbia. Dissertação (Mestrado em Ciência dos Materiais) - Instituto Militar de Engenharia, Exército Brasileiro, Ministério da Defesa, Rio de Janeiro, 143 f.1985.

[5] HASSAN, A. M.; AWAAD, M.; BONDIOLI, F.; NAGA, S. M. Densification behavior and mechanical properties of niobium-oxide-doped alumina ceramics. Journal of Ceramic Science and Technology, v. 5, p. 51 - 56, 2014.

[6] HSU, Y.; WANG, S.; WANG, Y.; CHEN, S. Effect of niobium doping on the densification and grain growth in alumina. Ceramics International, v. 34, p. 1183 1187, 2008.

[7] LAYDEN, G. K. The System Al2O3-Nb205. Journal of the American Ceramic Society, v. 46, p. 506, 1963. 